Am. J. Trop. Med. Hyg., 33(3), 1984, pp. 414-419

Copyright (C) 1984 by The American Society of Tropical Medicine and Hygiene

\title{
DEVELOPMENT OF ONCHOCERCA VOLVULUS LARVAE IN SIMULIUM PINTOI IN THE AMAZONAS REGION OF VENEZUELA*
}

\author{
HIROYUKI TAKAOKA,† HIROSHI SUZUKI,‡ SHINICHI NODA,§ ISAO TADA,\| \\ MARIA G. BASÁNEZ,** AND LUIS YARZẢBAL** \\ $\dagger$ Division of Medical Zoology, Medical College of Oita, Oita, Japan, $\ddagger$ Department of Virology, \\ Institute for Tropical Medicine, Nagasaki University, Nagasaki, Japan, \\ $\$$ Department of Medical Zoology, Faculty of Medicine, \\ Kagoshima University, Kagoshima, Japan, ||Department of \\ Parasitic Diseases, School of Medicine, Kumamoto \\ University, Kumamoto, Japan, and **Section of \\ Parasitic Immunology, National Institute of \\ Dermatology, Caracas, Venezuela
}

\begin{abstract}
The intake and development of Onchocerca volvulus in Simulium pintoi from the Parima mountain region of the Federal Territory of Amazonas in Venezuela, were studied experimentally. When wild females fed on the lower half of the legs and lower third of the back of an onchocerciasis patient harboring 23 and 264 microfilariae per skin snip, respectively, at each site, an average (median) of 14 (range, 1-77) and 245 (range, 58-495) microfilariae was ingested. However, within 24 hours of microfilarial ingestion a mortality of $47 \%$ (16/34 flies) was observed in the group of flies which fed on the back, as compared with $2 \%(2 / 101$ flies) in the other group which fed on the legs. At a temperature varying between $16^{\circ} \mathrm{C}$ and $24^{\circ} \mathrm{C}$, the development of $O$. volvulus larvae in $S$. pinto $i$ was synchronous and orderly; no abnormal nor deformed larvae were observed. Third-stage larvae were first seen in the head of flies dying between 8 and 9 days after microfilarial ingestion, and 98 of 100 larvae recovered from days 10-16 were in the third stage. The proportions of females harboring third-stage larvae among flies which lived through day 8 in the two groups which fed on the legs and back, respectively, were 55\% (21/38 flies) and 63\% (5/8 flies). Although only two of five positive flies in the latter group contained third-stage larvae in the head ( 1 and 12 , respectively), $71 \%$ (15/21 positive flies) of the former group had an average of 2.7 third-stage larvae in the head (range, 1-10). In conclusion, it is suggested that $S$. pintoi is an efficient vector of $O$. volvulus due to its high susceptibility, in spite of the high mortality caused by an excessive intake of microfilariae.
\end{abstract}

In addition to the classical onchocerciasis foci in the northern coastal range of Venezuela, Rassi et al. ${ }^{1}$ discovered a new focus in the southern region of this country (the Federal Territory of Amazonas), bordering the northern Territory of Roraima in Brazil where onchocerciasis is also endemic among the Yanomama Indian Tribe. The same authors incriminated Simulium pintoi d'Andretta and d'Andretta and $S$. cuasisanguineum Ramirez Pérez, Yarzábal and Peterson (misidentified at that time as $S$. amazonicum

Accepted 17 November 1983.

* This study was supported by the grant "Oversea Scientific Research" from the Ministry of Education, Culture and Science, Japan (Nos. 57041041 and $58043041)$ and by grants from the National Council for Scientific and Technological Research (No. S1-1128) and PROICET Amazonas of Venezuela.
Goeldi' ${ }^{2}$ as the vectors on the basis that these two blackfly species were most abundant and were naturally infected with infective larvae of Onchocerca volvulus.' However, no detailed information on the vectorial capacity of these two blackfly species was available, though this is essential for the assessment of their epidemiological importance in the transmission of onchocerciasis in nature.

The present study was therefore conducted to study the susceptibility of $S$. pintoi to infection with $O$. volvulus.

\section{MATERIALS AND METHODS}

This study was carried out in October 1982, at Parima $\mathrm{B}\left(02^{\circ} 55^{\prime} \mathrm{N}, 64^{\circ} 14^{\prime} \mathrm{W}\right)$ in the Venezuelan slope of the Parima mountain range, near the Brazil-Venezuela border. This area (about $950 \mathrm{~m}$ above sea level) lies in a zone of savanna, 


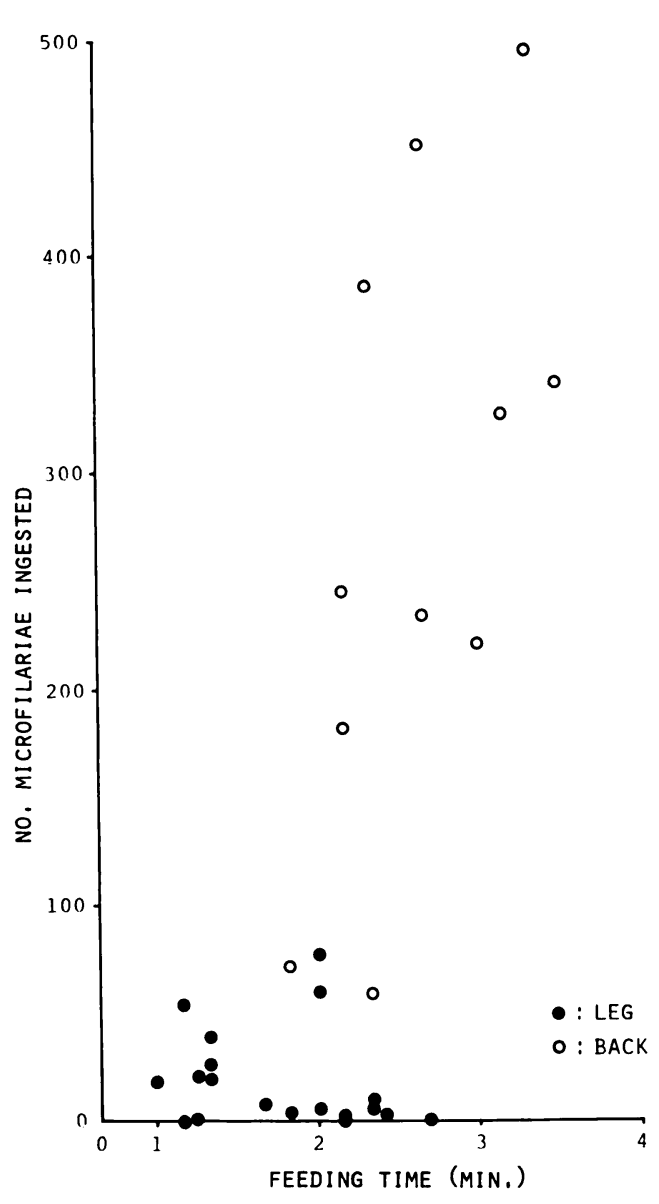

Figure 1. Number of the Onchocerca volvulus microfilariae ingested by Simulium pintoi females which fed on the legs and back of an onchocerciasis patient. in relation to the feeding time.

adjacent to the tropical forests which extend vastly westwards. Approximately 200 Yanomama Indians from the Niayoba-teri group and a few missionary families are resident at Parima B, and the prevalence rate for onchocerciasis was $73.9 \%$ by the skin-snipping method. ${ }^{3}$ The predominant man-biting blackfly species was $S$. pintoi, comprising $94 \%$ of the total catches. The natural infection rate of unfed female $S$. pintoi was $4.7 \%$ (7/477 flies dissected) for all stages of larvae and $0.2 \%$ ( $1 / 477$ flies dissected) for infective larvae of $O$. volvulus.

Female $S$. pintoi were captured while feeding on a volunteer (male Yanomama Indian) with onchocerciasis. In view of the fact that $S$. pintoi has a predilection for feeding on the lower parts of the human body, and the Yanomaman people, who are undressed or wear minimum cloths to cover the outer genital organ, usually rest in a seated posture on the ground, all engorged females were collected from the lower half of the legs and lower third of the back of the volunteer while he was seated on the ground. The numbers of microfilariae in the volunteer's skin per skin snip from the iliac and foot regions, taken with a corneoscleral punch (Holth type), were 264 and 23 , respectively. To assess microfilarial intake, 30 fully-fed females were killed and preserved in $70 \%$ ethanol after their engorgement time was measured. All other engorged females were collected and maintained individually in a polypropylene tube, using a method previously described. ${ }^{4}$ All tubes were placed in plastic boxes which were wrapped in turn in a wet towel and then put into a plastic bag to promote high humidity. These flies were kept at a temperature varying between $16^{\circ} \mathrm{C}$ and $24^{\circ} \mathrm{C}$, dead females being removed every 24 hours and stored in $70 \%$ ethanol solution for later dissection. Dissection of preserved blackflies for microfilarial intake was done using the technique of Nakamura. ${ }^{5}$ All other preserved samples were divided into head, thorax and abdomen and dissected in a drop of Giemsa solution on a glass slide under a binocular microscope, as previously described. ${ }^{6}$ The number of larvae in each part of the body was counted, and their stages of development were determined by the size and morphological features defined by Duke. ${ }^{7}$

\section{RESULTS}

Intake of $\mathrm{O}$. volvulus microfilariae by $\mathrm{S}$. pintoi

There was considerable variation in microfilarial intakes among individual females (Fig. 1). Of 19 females which fed on the lower half of the legs, $84 \%$ were positive, and contained an average (median) of 14 microfilariae per fly (range, 1-77 microfilariae). On the other hand, all 11 females which fed on the back harbored microfilariae; microfilarial intake ranged from 58 to 495 microfilariae per fly, with an average of 245 microfilariae.

The feeding time differed, depending on the body parts of the volunteer on which flies fed. An average of $1.8 \mathrm{~min}$ (range, $1.0-2.7 \mathrm{~min}$ ) and $2.5 \mathrm{~min}$ (range, $1.8-3.5 \mathrm{~min}$ ) was required by the two groups of flies which fed on the legs and 
TABLE 1

Development of Onchocerca volvulus larvae in Simulium pintoi which fed on the lower half of the legs of a carrier of $\mathrm{O}$. volvulus microfilariae and were kept at a temperature varying between $16^{\circ} \mathrm{C}$ and $24^{\circ} \mathrm{C}$

\begin{tabular}{|c|c|c|c|c|c|c|c|c|c|}
\hline \multirow{2}{*}{$\begin{array}{l}\text { Days post- } \\
\text { infection }\end{array}$} & \multirow{2}{*}{$\begin{array}{c}\text { No. } \\
\text { flies } \\
\text { examined }\end{array}$} & \multirow{2}{*}{$\begin{array}{c}\text { No. } \\
\text { flies } \\
\text { with } \\
\text { larvae }\end{array}$} & \multirow{2}{*}{$\begin{array}{c}\text { Total } \\
\text { no. } \\
\text { larvae }\end{array}$} & \multicolumn{2}{|c|}{$\begin{array}{l}\text { No. larvae/ } \\
\text { positive fly }\end{array}$} & \multicolumn{4}{|c|}{ No. (\%) stage of larvae* } \\
\hline & & & & Mean & (Range) & Mf. & $\mathbf{L}_{\mathbf{1}}$ & $L_{2}$ & $\mathrm{~L}_{3}$ \\
\hline 1 & 2 & 1 & 4 & 4 & (4) & $4(100)$ & $0(0)$ & $0(0)$ & $0(0)$ \\
\hline 2 & 4 & 2 & 42 & 21 & $(2-40)$ & $39(93)$ & $3(7)$ & $0(0)$ & $0(0)$ \\
\hline 3 & 5 & 4 & 26 & 6.5 & $(1-17)$ & $7(27)$ & $19(63)$ & $0(0)$ & $0(0)$ \\
\hline 4 & 13 & 6 & 24 & 4 & $(1-11)$ & $2(8)$ & $22(92)$ & $0(0)$ & $0(0)$ \\
\hline 5 & 12 & 10 & 22 & 2.2 & $(1-4)$ & $2(9)$ & $16(73)$ & $3(14)$ & $1(4) \dagger$ \\
\hline 6 & 10 & 3 & 8 & 2.7 & $(1-6)$ & $0(0)$ & $2(25)$ & $6(75)$ & $0(0)$ \\
\hline 7 & 7 & 5 & 10 & 2 & $(1-3)$ & $0(0)$ & $0(0)$ & $9(90)$ & $1(10) \dagger$ \\
\hline 8 & 10 & 7 & 22 & 3 & $(1-6)$ & $1(5)$ & $1(5)$ & $20(90)$ & $0(0)$ \\
\hline 9 & 6 & 5 & 10 & 2 & $(1-3)$ & $0(0)$ & $0(0)$ & $8(80)$ & $2(20)$ \\
\hline 10 & 6 & 2 & 6 & 3 & $(2-4)$ & $0(0)$ & $0(0)$ & $0(0)$ & $6(100)$ \\
\hline 11 & 5 & 4 & 8 & 2 & $(1-4)$ & $0(0)$ & $0(0)$ & $0(0)$ & $8(100)$ \\
\hline 12 & 5 & 3 & 10 & 3.3 & $(1-6)$ & $0(0)$ & $0(0)$ & $0(0)$ & $10(100)$ \\
\hline 13 & 7 & 4 & 19 & 4.7 & $(1-9)$ & $0(0)$ & $0(0)$ & $0(0)$ & $19(100)$ \\
\hline 14 & 6 & 4 & 11 & 2.7 & $(1-7)$ & $0(0)$ & $0(0)$ & $0(0)$ & $11(100)$ \\
\hline 15 & 2 & 2 & 12 & 6 & $(1-11)$ & $0(0)$ & $0(0)$ & $0(0)$ & $12(100)$ \\
\hline 16 & 1 & 1 & 1 & 1 & (1) & $0(0)$ & $0(0)$ & $0(0)$ & $1(100)$ \\
\hline Total & 101 & 63 & 235 & 3.7 & $(1-40)$ & $55(23)$ & $63(27)$ & $46(20)$ & $71(30)$ \\
\hline
\end{tabular}

back, respectively. However, apparently no correlation was observed between microfilarial intake and feeding time, as shown in Figure 1.

Development of O. volvulus larvae in S. pintoi

In both groups, third-stage larvae were first seen in the head of flies dying between 8 and 9 days after ingestion of microfilariae. The development of $O$. volvulus larvae in $S$. pintoi was synchronous and orderly (Tables 1 and 2 ), as evidenced by the fact that of 100 larvae recovered during days 10-16, 98 had already developed to the third stage, although, as an exception, a few microfilariae and first-stage larvae were still found on days 8 and 9 .

The infection rate and average number of larvae per positive fly were markedly different between the two groups of flies with different microfilarial intakes. Of 101 females which fed on the legs, $62 \%$ were positive with a mean of 3.7 larvae per positive fly (range, 1-40) (Table 1). In comparison, $97 \%$ (33/34 flies) of the females which fed on the back were positive, and the average number of larvae per positive fly examined during days 2-11 was 12.2 (Table 2).

The proportions of female $S$. pintoi harboring third-stage larvae among flies which lived through day 8 in the groups which fed on the legs and back were 55\% (21/38 flies) and 63\% (5/8 flies), respectively (Table 3 ). Two of five positive flies which fed on the back contained, respectively, one and 12 third-stage larvae in the head (Table 3). These amounted to $40 \%$ of the third-stage larvae recovered (Table 4). On the other hand, $71 \%$ (15/21 flies) of the positive flies which fed on the legs harbored third-stage larvae (1-10 larvae, avg. 2.7) in the head (Table 3); these represented $57 \%$ of the third-stage larvae recovered (Table 4). The average length of the third-stage larvae thus obtained was $553.0 \mu \mathrm{m}$ (range 457.2$704.6 \mu \mathrm{m}$ ), and the width $18.6 \mu \mathrm{m}$ (range 17.4 $20.1 \mu \mathrm{m})$.

Mortality of S. pintoi within 24 hours and 8 days after intake of microfilariae

Within 24 hours of ingestion of microfilariae, a high mortality (47\%) was observed in the group of flies which fed on the back, whereas only $2 \%$ of the females in the other group, which fed on the legs, died (Fig. 2). On the other hand, in the group of flies which fed on the back the mortality rate during days $2-8(56 \%)$ was slightly lower than that of the group which fed on the legs (62\%), although the worm burden per fly in the former group was three times as high as that in the latter. 
TABLE 2

Development of Onchocerca volvulus larvae in Simulium pintoi which fed on the lower third of the back of a carrier of $\mathrm{O}$. volvulus microfilariae and were kept at a temperature varying between $16^{\circ} \mathrm{C}$ and $24^{\circ} \mathrm{C}$

\begin{tabular}{|c|c|c|c|c|c|c|c|c|c|}
\hline \multirow{2}{*}{$\begin{array}{c}\text { Days post- } \\
\text { infection }\end{array}$} & \multirow{2}{*}{$\begin{array}{c}\text { No. } \\
\text { flies } \\
\text { examined }\end{array}$} & \multirow{2}{*}{$\begin{array}{c}\text { No. } \\
\text { flies } \\
\text { with } \\
\text { larvae }\end{array}$} & \multirow{2}{*}{$\begin{array}{c}\text { Total } \\
\text { no. } \\
\text { larvae }\end{array}$} & \multicolumn{2}{|c|}{ No. larvae/positive fly } & \multicolumn{4}{|c|}{ No. (\%) stage of larvae* } \\
\hline & & & & Mean & (Range) & Mf. & $L_{1}$ & $L_{2}$ & $L_{3}$ \\
\hline 1 & 16 & 16 & 3,531 & 220.7 & $(25-807)$ & $3,531(100)$ & $0(0)$ & $0(0)$ & $0(0)$ \\
\hline 2 & 1 & 1 & 29 & 29 & (29) & $20(69)$ & $9(31)$ & $0(0)$ & $0(0)$ \\
\hline 3 & 0 & - & - & - & $(-)$ & $-(-)$ & $-(-)$ & $-(-)$ & $-(-)$ \\
\hline 4 & 2 & 2 & 72 & 36 & $(9-63)$ & $19(26)$ & $54(74)$ & $0(0)$ & $0(0)$ \\
\hline 5 & 1 & 1 & 4 & 4 & (4) & $0(0)$ & $1(25)$ & $3(75)$ & $0(0)$ \\
\hline 6 & 1 & 1 & 4 & 4 & (4) & $0(0)$ & $1(25)$ & $3(75)$ & $0(0)$ \\
\hline 7 & 3 & 3 & 23 & 7.7 & $(2-14)$ & $0(0)$ & $1(4)$ & $22(96)$ & $0(0)$ \\
\hline 8 & 2 & 2 & 9 & 8.5 & $(2-7)$ & $1(11)$ & $1(11)$ & $7(78)$ & $0(0)$ \\
\hline 9 & 3 & 3 & 34 & 11.3 & $(8-16)$ & $1(3)$ & $1(3)$ & $30(88)$ & $2(6)$ \\
\hline 10 & 4 & 4 & 33 & 8.2 & $(1-20)$ & $0(0)$ & $0(0)$ & $2(6)$ & $31(94)$ \\
\hline 11 & 1 & 0 & - & - & $(-)$ & $-(-)$ & $-(-)$ & $-(-)$ & $-(-)$ \\
\hline Total & 34 & $\begin{array}{l}33 \\
17 \dagger\end{array}$ & $\begin{array}{l}3,739 \\
208 \dagger\end{array}$ & $\begin{array}{c}113.3 \\
12.2 \dagger\end{array}$ & $\begin{array}{l}(1-807) \\
(1-63) \dagger\end{array}$ & $3,572(96)$ & $68(2)$ & $67(2)$ & $33(1)$ \\
\hline
\end{tabular}

\section{DISCUSSION}

Simulium pintoi has been incriminated as the main vector of onchocerciasis in the southern Venezuelan focus due to its predominance and natural infection with infective larvae of $O$. volvulus. ' Further, the level of natural infection (2\%) repored by Rassi et al.' suggested an efficient capacity of this blackfly species to transmit $O$. volvulus larvae. However, no detailed information on the vectorial capacity of this species has been available.

In the present study, it has been demonstrated that $S$. pintoi from Parima B of the Parima mountain region, Venezuela, supports the development of the microfilariae of $O$. volvulus to the infective stage. Furthermore, this species is judged to be highly susceptible to infection with

TABLE 3

Number and proportion of female Simulium pintoi harboring third-stage larvae $\left(L_{3}\right)$ in any part of the body and in the head, respectively, and the numbers of $L_{3}$ in the head per infected fly, among flies dissected during days 9-16 after ingestion of infective blood-meal

\begin{tabular}{lccccc}
\hline & $\begin{array}{c}\text { Days } \\
\text { Body }\end{array}$ & $\begin{array}{c}\text { post- } \\
\text { region } \\
\text { infec- } \\
\text { bitten }\end{array}$ & $\begin{array}{c}\text { No. flies } \\
\text { tith } L_{y} / \text { no. } \\
\text { dissected }(\%)\end{array}$ & $\begin{array}{c}\text { No. flies } \\
\text { with } \mathrm{L}_{3} \text { in } \\
\text { head/no. with } \\
\mathrm{L}_{3}(\%)\end{array}$ & $\begin{array}{c}\text { No. } \mathrm{L}_{3} \\
\text { in head per } \\
\text { infected fly }\end{array}$ \\
\cline { 5 - 6 } & Back & $9-11$ & $5 / 8(63)$ & $2 / 5(40)$ & $6.5(1-12)$ \\
Legs & $9-16$ & $21 / 38(55)$ & $15 / 21(71)$ & $2.7(1-10)$ \\
\hline
\end{tabular}

this filarial parasite, as larval development was synchronous, no abnormal or deformed larvae were observed, and nearly all the larvae recovered on day 10 or later were in the third stage.

The proportion of flies with third-stage larvae in the head among survivors was $40 \%$ in the group of flies which fed on the back. This low rate is probably attributable to the fact that all flies died by day 11 -the period being not long enough to allow the third-stage larvae to migrate to the head. In fact, the corresponding rate in the other group which fed on the legs in which many flies survived several days beyond day 9 was high (71\%). Therefore, it is suggested that the possibility for infective larvae to be inoculated into man by $S$. pintoi is high.

On the other hand, our data reveal that high intake of microfilariae is lethal to $S$. pintoi within the first $\mathbf{2 4}$ hours of infection. This phenomenon

TABLE 4

Distribution of third-stage larvae $\left(L_{3}\right)$ of Onchocerca volvulus in the body of female Simulium pintoi which were dissected during days 9-16 after ingestion of infective blood-meal

\begin{tabular}{lccccc}
\hline \multirow{2}{*}{$\begin{array}{c}\text { Body } \\
\text { region } \\
\text { bitten }\end{array}$} & $\begin{array}{c}\text { Days } \\
\text { post-in- } \\
\text { fection }\end{array}$ & $\begin{array}{c}\text { Total } \\
\text { no. } \mathrm{L}_{3} \\
\text { recov- } \\
\text { ered }\end{array}$ & \multicolumn{3}{c}{ No. (\%) $\mathrm{L}_{3}$ found in } \\
\cline { 5 - 7 } Back & $9-10$ & 33 & $13(40)$ & $10(30)$ & $10(30)$ \\
Legs & $9-16$ & 69 & $41(59)$ & $15(22)$ & $13(19)$ \\
\hline
\end{tabular}




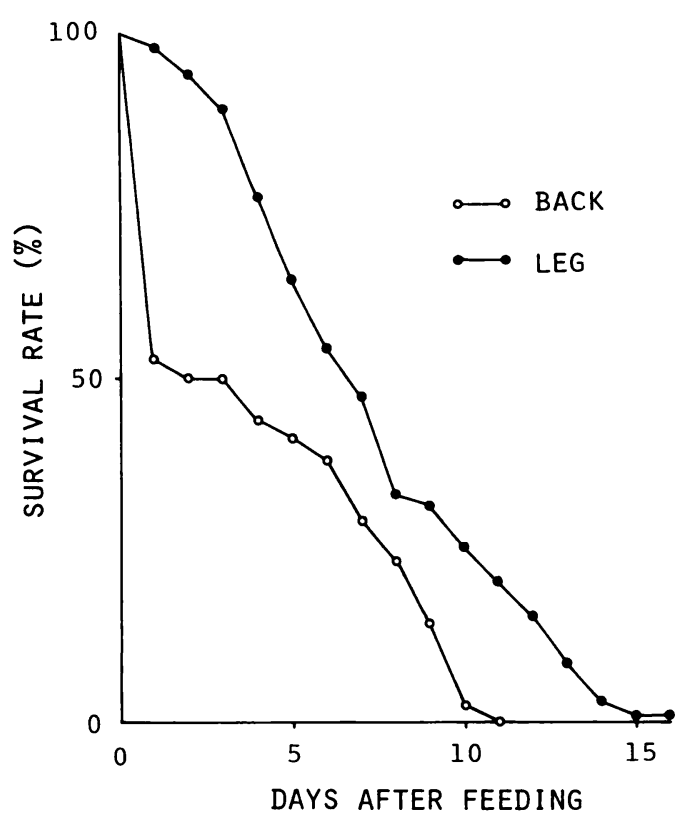

FIGURE 2. Survivorship curves of the two groups of Simulium pintoi females which fed on the legs and back of an onchocerciasis patient and were kept at a temperature varying between $16^{\circ} \mathrm{C}$ and $24^{\circ} \mathrm{C}$.

is explained by the absence of toothed buccopharyngeal armature which has been reported to be a destructive apparatus against ingested microfilariae - thus preventing them from damaging the midgut or other organs of the host insect. ${ }^{8}$ In lacking such an armature, ${ }^{2}$ this species is similar to $S$. metallicum in Guatemala, which often exhibited high mortality immediately after ingestion of many microfilariae. ${ }^{8-10}$ In contrast, it is noteworthy that on and after day 2 post-infection survival of $S$. pinto $i$ seems unlikely to be affected by the presence of parasites in the thorax or head. As many as 20 third-stage larvae were observed in one fly examined on day 10 (Table 2).

Considering the above findings, it is suggested that $S$. pintoi is an efficient experimental vector of $O$. volvulus, although high mortality is caused if large numbers of microfilariae are ingested.

During the present study, it was observed that $S$. pinto $i$ was the most abundant man-biting blackfly species in the region of Sierra Parima and its foothills (250-1,000 $\mathrm{m}$ in altitude), whereas this species was replaced by the $S$. amazonicum-sanguineum group in the lowlands (100-
$200 \mathrm{~m}$ in altitude) along the main channel of the Orinoco River. Moreover, S. pintoi was shown to have high anthropophily, tenacious biting behavior and very short engorgement time. These observations, as well as the results obtained in the present experiment, indicate that $S$. pinto $i$ plays an important role in onchocerciasis transmission in the southern Venezuelan focus. The exception would be in lowland areas along the Orinoco River, where certain species of the $S$. amazonicum-sanguineum group probably would play an important role as the vector.

\section{ACKNOWLEDGMENTS}

The authors wish to express their gratitude to Dr. A. Sánchez C., Governor, Territorio Federal de Amazonas, Venezuela, for his support during this study. We are grateful to Dr. M. Baba, Miss C. Aoki and Miss K. Ogata, Medical College of Oita, Japan, for their help in dissecting blackflies.

\section{REFERENCES}

1. Rassi, E., Monzon, H., Castillo, M., Hernandez, I., Ramírez Pérez, J., and Convit, J., 1977. Discovery of a new onchocerciasis focus in Venezuela. Bull. Pan. Am. Health Org., 11: 41-63.

2. Ramírez Pérez, J., Yarzábal, L. and Peterson, B., 1982. La Simulofauna del Territorio Federal Amazonas (Venezuela). Proicet Amazonas, $\mathrm{Ca}$ racas.

3. Yarzábal, L., Arango, H., Botto, C., Jaimes, J. L., Sánchez Beaujon, R., and Rago, L. M., 1983. Nuevas observaciones sobre la endemia oncocercosica de la Sierra Parima, Territorio Federal Amazonas, Venezuela. Pages 3-19, in Filariasis humanas en Territorio Federal Amazonas, Venezuela. Proicet Amazonas, Caracas.

4. Takaoka, H., Ochoa A., J. O., Juarez, E. L., and Hansen, K. M., 1982. Effects of temperature on development of Onchocerca volvulus in Simulium ochraceum, and longevity of the simuliid vector. J. Parasitol., 68: 478-483.

5. Nakamura, Y., 1964. Experimental studies on the role of Aedes togoi in the transmission of bancroftian filariasis. 1. Number of microfilariae taken up by the female and their movement in her body. Endemic Dis. Bull. Nagasaki Univ., 6: 25-33.

6. Takaoka, H., 1982. Observations on the bionomics of larval and man-biting female populations of Simulium horacioi, a new potential vector of Onchocerca volvulus in Guatemala. Jap. J. Trop. Med. Hyg., 10: 49-62.

7. Duke, B. O. L., 1968. Studies on factors influencing the transmission of onchocerciasis. V: The stages of Onchocerca volvulus in wild 'forest' $\mathrm{Si}$ mulium damnosum, the fate of the parasites in 
the fly and the age-distribution of the biting population. Ann. Trop. Med. Parasitol., 62: 107116.

8. Omar, M. S., and Garms, R., 1975. The fate and migration of microfilariae of a Guatemalan strain of Onchocerca volvulus in Simulium ochraceum and $S$. metallicum, and the role of the buccopharyngeal armature in the destruction of microfilariae. Tropenmed. Parasitol., 26: 183-190.

9. De León, J. R., and Duke, B. O. L., 1966. Ex- perimental studies on the transmission of Guatemalan and West African strains of Onchocerca volvulus by Simulium ochraceum, S. metallicum and $S$. callidum. Trans. $R$. Soc. Trop. Med. Hyg., 60: 735-752.

10. Ito, S., Tanaka, I., and Ochoa A., J. O., 1980. Comparative studies on the affinities of two black flies, Simulium metallicum and $S$. ochraceum for the larvae of Onchocerca volvulus in Guatemala. Jap. J. Sanit. Zool., 31: 261-270. 